\title{
FOREWORD Special Issue on the 2012 TOUGH Symposium
}

\author{
George J. Moridis $^{1}$ • Nicolas Spycher ${ }^{1}$
}

Published online: 16 April 2015

(C) Springer Science+Business Media Dordrecht (outside the USA) 2015

This Special Issue of Transport in Porous Media features selected papers from the 2012 TOUGH Symposium, which took place on September 17-19, 2012, in Berkeley, California, USA. Such symposia are held every 3 years and are a forum where users of the TOUGH family of numerical simulators meet for an open exchange on the code applications and recent enhancements. The acronym "TOUGH" stands for "Transport of Unsaturated Groundwater and Heat" and reflects the original geothermal focus of the code, which has over the years expanded into a family of multi-dimensional, multi-component models that are designed for the simulation of a wide range of coupled processes that include in their simplest realization the transport of fluids and heat in porous and/or fractured geologic media, and extend to a wide range more complex coupled processes such as chemical, geomechanical, geophysical, etc.

Since its first release in 1987 by a team of researchers at the Lawrence Berkeley National Laboratory headed by Karsten Pruess, the TOUGH family has been enriched by a large number of modules that describe a variety of important Equations-Of-State (EOS, involving various mass components), and has evolved to include several derivatives and descendants (e.g., EOS modules for multi-component volatile organic compounds; decay chains of multiple radionuclides, gas hydrates, tight and shale gas behavior, and supercritical $\mathrm{CO}_{2}$; modules for coupled multi-phase flow and reactive transport, and coupled thermo-hydrologicmechanical processes; inverse modeling for parameter estimation, sensitivity analysis, and uncertainty quantification; parallelization for multi-core PCs, workstation clusters, and supercomputers, etc). The TOUGH family of codes is currently used to address a wide spectrum of problems, which includes applications to geothermal reservoir engineering, nuclear waste disposal in geologic formations, geologic carbon sequestration, vadose zone hydrology, environmental remediation, oil and gas reservoir engineering with an emphasis on unconventional resources (such as hydrates, tight and shale gas and oil), and other coupled mass transport and

George J. Moridis, Nicolas Spycher-Guest Editors.

George J. Moridis gjmoridis@lbl.gov

1 Earth Sciences Division, Lawrence Berkeley National Laboratory, Berkeley, CA, USA 
energy transfer problems in complex subsurface geologic settings. The international TOUGH user community currently numbers almost 400 organizations (research laboratories, government agencies, private companies, universities, etc.) in over 60 countries.

The purpose of the symposium is to bring together users of the current members of the TOUGH family of codes (which includes TOUGH2, iTOUGH2, TMVOC, TOUGHREACT, TOUGH-FLAC, TOUGH+, TOUGH2-MP, p-TOUGH+ and more) for an open exchange on applications and recent code enhancements. Approximately 250 researchers and engineers from a dozen countries attended the 2012 TOUGH Symposium. The 114 papers presented by international researchers and research groups at the symposium covered a wide range of topics that include the following:

- Modeling of coupled (thermal, hydrological, chemical, mechanical, biological, geophysical) processes in porous and fractured geologic media

- Geologic carbon dioxide storage and utilization

- Geothermal reservoir engineering

- Performance assessment of nuclear waste repositories

- Hydrocarbon recovery from conventional and unconventional (hydrates, tight- and shalegas, shale oil) resources

- Critical zone hydrology, including vadose zone-atmosphere interaction

- Fate and transport of volatile organic compounds

- Reactive transport modeling for environmental remediation

- Water resources management, including surface water-groundwater interaction

- Design and analysis of laboratory and field experiments

- Automatic model calibration and uncertainty analysis

- Code verification and validation

- Enhanced process capabilities and user features

- Numerical methods, grid generation, and parallel computing

Twelve representative papers that cover a wide spectrum of subjects involved in the most important current applications of the TOUGH family of codes were selected for inclusion in this Special Issue of Transport in Porous Media. We hope that this Special Issue will be a valuable addition to the library of engineers, scientists, and technology specialists involved in various aspects of system behavior during flow and transport through complex geologic media, and especially to current and future users of the TOUGH codes.

In concluding, we would like to express our thanks and appreciation to the many paper authors, session organizers, and chairs that made the symposium an unequivocal success, and our gratitude to the various reviewers for their outstanding efforts in evaluating the papers and making the publication of this Special Issue possible. 